\title{
Performance of a Sensitivity Analysis on the Multi-Function Network Survey Vehicle (MFNSV)
}

\author{
K.V.D. Perera, P.N. Miskitha, J.P.H.P.K. Jayasekera, \\ C.P.S. Pathirana and K.S. Weerasekera
}

\begin{abstract}
Multi-Function Network Survey Vehicle (MFNSV) provides cutting-edge technology for obtaining highway pavement information such as; roughness, rutting, geometric data, road condition data as images and accurate distance measurements. The Hawkeye processing toolkit is used to process the data collected through a moving vehicle. The MFNSV manufacturer claims that the information is fairly accurate when the vehicle is driven within a speed range of 20 to $110 \mathrm{~km} / \mathrm{h}$.

Road pavement information was collected manually through accurate field measurements along 4 sample stretches on the A004 road, and the same information was collected through the MFNSV. The results obtained from the two methods were compared by carrying-out a sensitivity analysis test. The results of the sensitivity analysis showed that the information collected from all 4 sample test sites did not possess significant statistical differences between the data collected by the two methods.
\end{abstract}

Keywords: $\quad$ Pavement Failure Inspection, MFNS Vehicle, Sensitivity Analysis

\section{Introduction}

It was intended to conduct a sensitivity check on the Multi-Function Network Survey Vehicle (MFNSV) (see Figure 1) which provides cutting-edge technology for obtaining highway pavement information under local conditions. Data collected through the MFNSV is processed through the Hawkeye 2000 package installed on the MFNS vehicle. This study was possible due to the assistance rendered by the Planning Division of the Road Development Authority of Sri Lanka which presently uses the MFNSV for its highway pavement data collection operations. Sample data was collected manually as well as through the MFNSV and results were compared and differences were statistically checked.

According to the manufacturer, the following are some of the general applications of MFNSV [1]:

- Network and project level road and asset collection surveys

- Routine pavement monitoring surveys

- Roadside inventory and asset management

- Road geometry and mapping surveys

- Contractor quality control

- Road safety assessment

- Line marking reflectivity

- Airport runway inspections
Highway pavement information listed below was collected from the sample sites through manual surveys as well as from the MFNSV.

1. Crack areas (all types of cracks)

2. Defected patch areas

3. Ravelling areas

4. Pot-hole areas

5. Lane width

Thereafter samples obtained were compared with one another using statistical techniques and the differences were observed.

K. V. D.Perera, Undergraduate in BTech (Eng),Department of Civil Engineering, The Open University of Sri Lanka.

P.N. Miskitha, Undergraduate in BTech (Eng), Department of Civil Engineering, The Open University of Sri Lanka.

J. P. H. P. K. Jayasekera, Undergraduate in BTech (Eng), Department of Civil Engineering, The Open University of Sri Lanka.

C. P. S. Pathirana, BSc Special (Hons) (Ruhuna), M.Sc (SJP), M.Phil (Ruhuna), Senior Lecturer, Department of Mathematics \& Philosophy of Engineering, The Open University of Sri Lanka.

Eng. (Prof.) K. S. Weerasekera, IntPE(SL), CEng, FIE(Sri Lanka), BSc Eng (Moratuwa), MEngSc (UNSW), PhD (UNSW), MIE(Aust), CPEng, MIHT (UK), MASCE,

Chair \& Professor of Civil Engineering, Department of Civil Engineering, The Open University of Sri Lanka. 


\section{Methodology}

As already mentioned, Manual Data Collection and MFNS Vehicle Data Collection were carried-out at four selected road sections.

\section{Manual Road Inspection}

Under this method, one has to inspect the road visually and collect data manually by measuring each and every type of failures and their magnitude in relation to the chainage and fill the standard visual inspection form (see Appendix A) that was developed for this process.

Field observation data collected through visual inspection forms (i.e., Appendix A) are fed into the computer according to the format shown in Appendix B. The format given in Appendix B includes the chainage of the survey section, surface type, lane width, shoulder type, shoulder width, roughness, serious damages and all other defects, drainage type, drainage condition, road side information and space for any suitable comments. Cracks, serious damages, surface deformation and edge damages are recorded in linear meters. Potholes are recorded as numbers. If the field surveys are conducted by competent persons, the results obtained can be very accurate.

Though this form records the potholes in numbers and other failures in linear meters, to compare with the sensitivity of vehicle data, the areas of those failures had to be measured. If a pothole area was larger than $4 \mathrm{~m}^{2}$, it was recorded as a surface deformation. The minimum length of a survey section was $100 \mathrm{~m}$. However in special cases, the inspector had to increase the survey length. This is the most accurate method to inspect the road since it is done manually.

\section{Multi-Functional Network Survey Vehicle (MFNSV)}

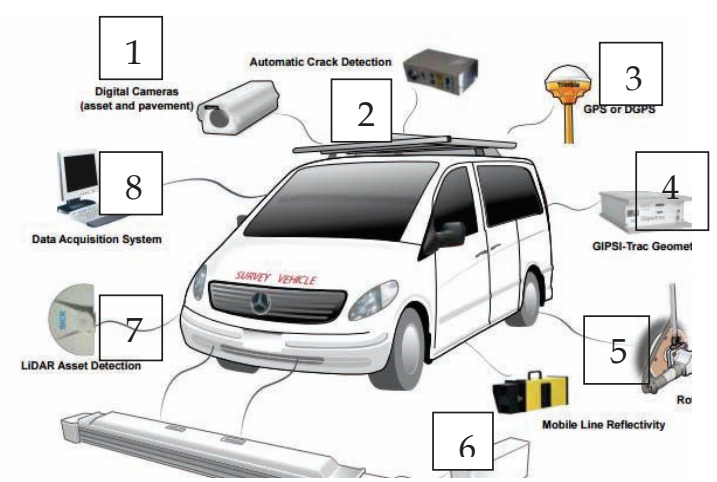

Figure 1 - Multi-Functional Network Survey Vehicle (MFNSV)
1. Digital Camera
2. Automatic Crack Detector
3. GPS or DGPS
4. GPSI - Track Geometry
5. Rotorpulser
6. Mobile Line Reflectivity
7. LIDAR Asset Detection
8. Data Acquisition System

\section{(Courtesy of Traffic\& Planning Division of RDA)}

This vehicle is of cutting-edge technology, and includes devices such as five numbers of high resolution digital cameras, a front laser mounting beam, side projection lasers, a rotorpulser, a data acquisition system, gipsy-track geometry, a GPS (Global Positioning System) and a DGPS (Differential Global Positioning System). Using those devices, details such as roughness, rutting, geometric data and road condition data can be obtained as images and distance measurements. The Hawkeye processing toolkit is used to process the data taken from this vehicle. To obtain accurate readings, the vehicle has to be driven on the road at a speed between $20 \mathrm{~km} / \mathrm{h}$ and 110 $\mathrm{km} / \mathrm{h}$.

Pavement data was collected from four sample stretches each of 200 meter length located on the A004 CRWB(Colombo, Ratnapura, Wellawaya and Batticaloa) road between Meepe and Avissawella. As indicated in Figure 2, four 200 meter stretches from $35 \mathrm{~km}, 40 \mathrm{~km}$, $45 \mathrm{~km}$ and $50 \mathrm{~km}$ posts were selected for the data collection.

\section{Failure Types}

$>$ Cracks - There are several types of cracks that can be seen on roads. i.e, longitudinal cracks, transverse cracks, diagonal cracks, block cracks and crocodile cracks. All of those cracks can be measured under this category.

$>$ Raveling - This is the removal of materials from the pavement surface.

> Potholes - Potholes are bowl-shaped holes. The distress progresses downwards into the lower layers of the pavement.

$>$ Defected patch areas where the failure of early treated are as that has taken place.

\section{Measurement of Failures}

During manual inspection, all failure areas were measured using steel tapes. In the MFNSV method, all failure areas were measured using the Hawkeye processing toolkit software. The area obtained from the software is presented below. 


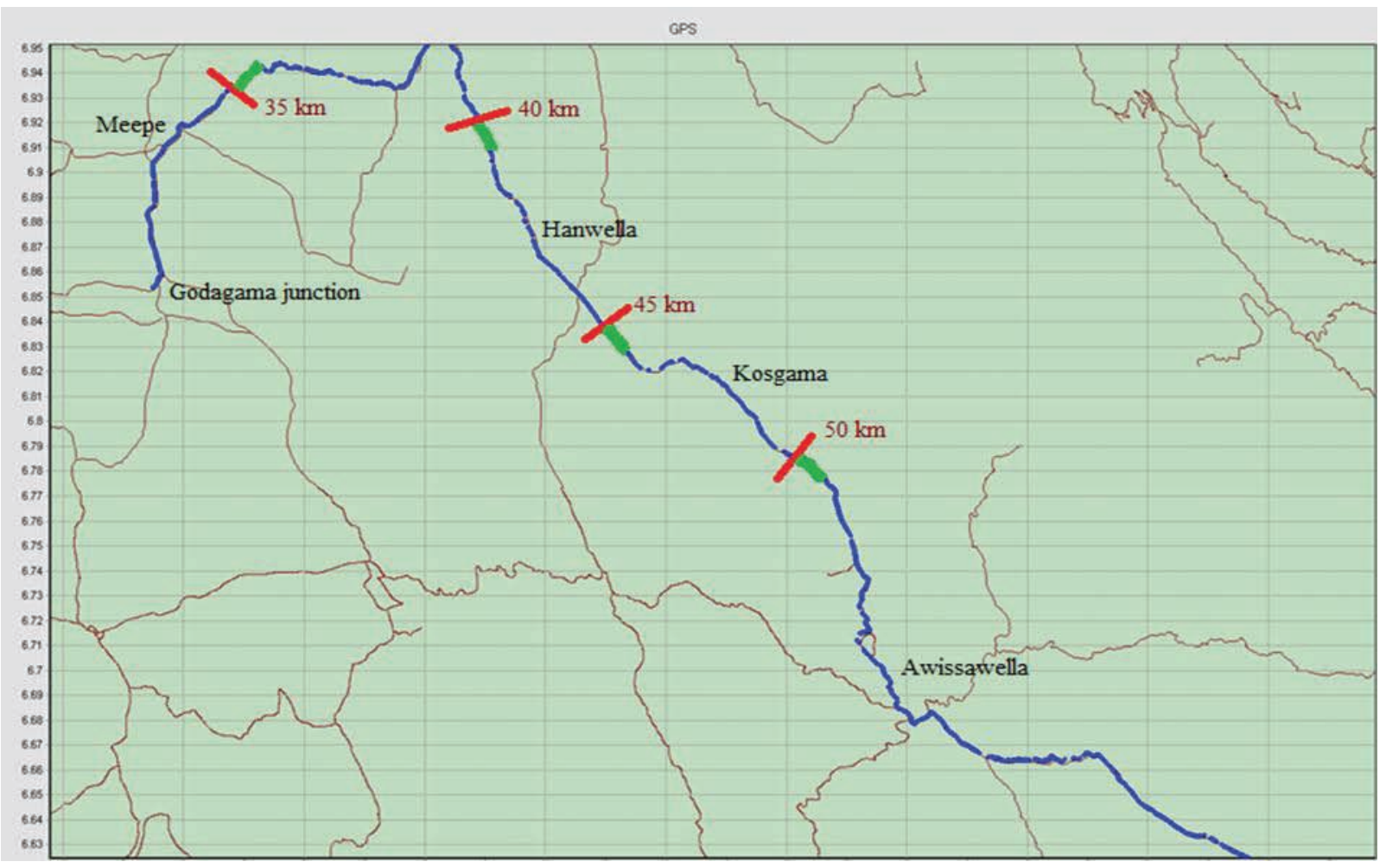

Figure 2 - Layout of the Study Area

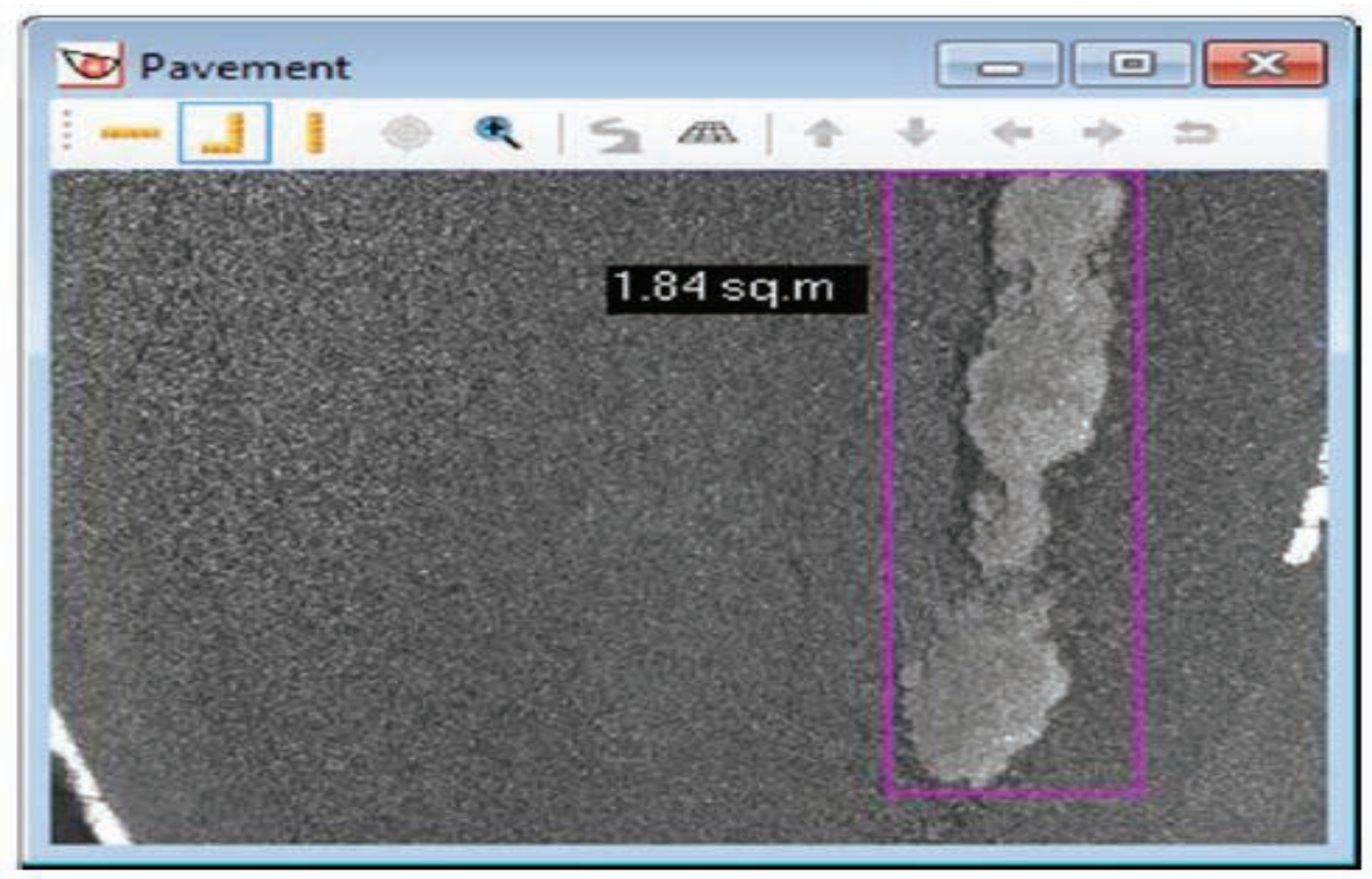

Figure 3 - Crack area from the software 


\section{Data Analysis and Results}

Vehicle inspection survey data was collected to find out the total failure percentages according to each failure type with $200 \mathrm{~m}$ samples taken at every $5 \mathrm{~km}$ interval by looking at all pictures of the road using the software. All failure areas identified during vehicle inspection were analysed using the Hawkeye software tool. Its calculation part is shown below. All failure areas identified during manual inspection were measured using steel tapes and the corresponding failure percentages were calculated (Figure 3). Thereafter, the failure percentages were compared and a sensitivity analysis of pavement inspection methods with $200 \mathrm{~m}$ samples taken at every $5 \mathrm{~km}$ interval was done. The process followed in obtaining failure percentages of the first section $(35 \mathrm{~km}-35.2$ $\mathrm{km}$ ) is described below in which only the $35.001 \mathrm{~km}$ chainage has been considered for the sample calculation.

In manual inspection,

$\begin{array}{ll}\text { Crack areas } & =0 \\ \text { Defected patch areas } & =0 \\ \text { Raveling areas =1.5 x 1.67 } & =2.51 \mathrm{~m}^{2} \\ \text { Pothole area } & =0 \\ \text { Lane width } & =3.8 \mathrm{~m} \\ & \\ \text { In vehicle inspection, } & =0 \\ \text { Crack areas } & =0 \\ \text { Defected patch areas } & =2.514 \mathrm{~m}^{2} \\ \text { Raveling areas } & =0 \\ \text { Pothole area } & =3.8 \mathrm{~m} \\ \text { Lane width } & \end{array}$

Failure percentage $=\frac{\text { Total failure area } x 100 \%}{\text { Total area of one section }}$.

Consider the $35.001 \mathrm{~km}$ chainage in Table 1 which is shown in APPENDIX B relevant to manual inspection survey results.

$\begin{array}{ll}\text { Length of one sub section } & =4 \mathrm{~m} \\ \text { Width of one sub section } & =3.8 \mathrm{~m} \\ \text { Area of one sub section } & =15.2 \mathrm{~m}^{2} \\ \text { Total failure area } & =2.510 \mathrm{~m}^{2} \\ \begin{array}{l}\text { Failure } \\ \text { percentage }\end{array} & =\underline{2.510 \times 100} \\ & =\underline{16.51 \%}\end{array}$

Consider the $35.001 \mathrm{~km}$ chainage in Table 1 which is shown in Appendix B Band which relates to visual inspection survey results from the vehicle.

$\begin{array}{ll}\text { Length of one sub section } & =4 \mathrm{~m} \\ \text { Width of one sub section } & =3.8 \mathrm{~m} \\ \text { Area of one sub section } & =15.2 \mathrm{~m}^{2} \\ \text { Total failure area } & =2.514 \mathrm{~m}^{2} \\ \begin{array}{l}\text { Failure } \\ \text { percentage }\end{array} & =\underline{2.514 \times 100} \\ & =\underline{16.54 \%}\end{array}$

\section{Sensitivity Tests}

\subsection{Sensitivity Analysis}

The vehicle and manual inspection surveys were compared with respect to total failure percentages. Thereafter, the sensitivity of the vehicle was checked through sensitivity analysis. Each $200 \mathrm{~m}$ was then divided into $4 \mathrm{~m}$ intervals and 50 data sets for manual inspection and 50 data sets for vehicle inspection were obtained for each section. SPSS software was used to check the statistical significance of the test. Results were obtained based on the t-test. For the t-test, both $95 \%$ and $99 \%$ confidence intervals were used.

Correlation analysis is used to quantify the association between two continuous variables (e.g., between an independent and a dependent variable or between two independent variables). To find the correlation coefficient, the following equation can be used.

$r=\frac{\sum_{i=1}^{n}\left(x_{i}-\bar{x}\right)\left(y_{i}-\bar{y}\right)}{\sqrt{\sum_{i=1}^{n}\left(x_{i}-\bar{x}\right)^{2} \sum_{i=1}^{n}\left(y_{i}-\bar{y}\right)^{2}}}$

where,

$$
\begin{aligned}
& n=\text { sample size } \\
& x_{i}=\text { independent variable } \\
& y_{\mathrm{i}}=\text { dependent variable }
\end{aligned}
$$

Regression analysis is a related technique to assess the relationship between an outcome variable and one or more risk factors or confounding variables.

In regression analysis, the dependent variable is denoted by " $y$ " and the independent variables 
by " $x$ ". Many techniques for carrying out a regression analysis have been developed.

Linear regression equation as[2]:

$\mathrm{y}_{i}=a x_{i}+b$

where,

$$
\begin{gathered}
a=\frac{n \sum_{i=1}^{n} x_{i} y_{i}-\sum_{i=1}^{n} x \sum_{i=1}^{n} y}{n \sum_{i=1}^{n} x^{2}-\left(\sum_{i=1}^{n} x\right)^{2}} \\
b=\bar{y}-b \bar{x}
\end{gathered}
$$

where, $\bar{x}=\frac{\sum_{i=1}^{n} x}{n}, \bar{y}=\frac{\sum_{i=1}^{n} y}{n}$

Symbol $a$ represents the slope or gradient of the line, and is also sometimes called the regression coefficient while symbol $b$ represents the intercept that is the value of $y$ where the line crosses the y axis.

Null Hypothesis is a statement that the value of the population parameter is no different from that which is equal to a specified value. Statically, a null hypothesis may be stated as;

$\mathrm{H}_{\mathrm{o}}: \mu_{1}=\mu_{2}$

Where $\mu_{1}$ and $\mu_{2}$ are population means.

The Alternative Hypothesis is a statement that there is some difference in the two populations. It can be stated as

$\mathrm{H}_{\mathrm{a}}: \mu_{1} \neq \mu_{2}$
For our study, manual inspection readings were taken as $\mu_{1}$ and vehicle inspection readings were taken as $\mu_{2}$.

The output taken from the SPSS software is discussed below. It shows that the accuracy of the MFNSV is high.

Figure 4 shows the failure percentages of the first section (35 km- $35.2 \mathrm{~km}$ ) which were selected for the study. The $X$ axis represents 50 parts while the $Y$ axis represents failure percentages of each part.

Table 1 and 2 represent the tabulations of the mean, standard deviation, standard error mean, confidence interval of the difference, $t$ value, degree of freedom and the significant value of two tailed test for the $95 \%$ and $99 \%$ confidence intervals respectively.

The paired sample $t$ test results as shown in Table 1 above will appear in the SPSS output window. The $p$-value is 0.021 and $\alpha$ value is 0.05 . The $p$-value is greater than 0.05 which implies that the hypothesis has not been rejected. Therefore, there is no difference between manual and vehicle readings at $95 \%$ confidence level.

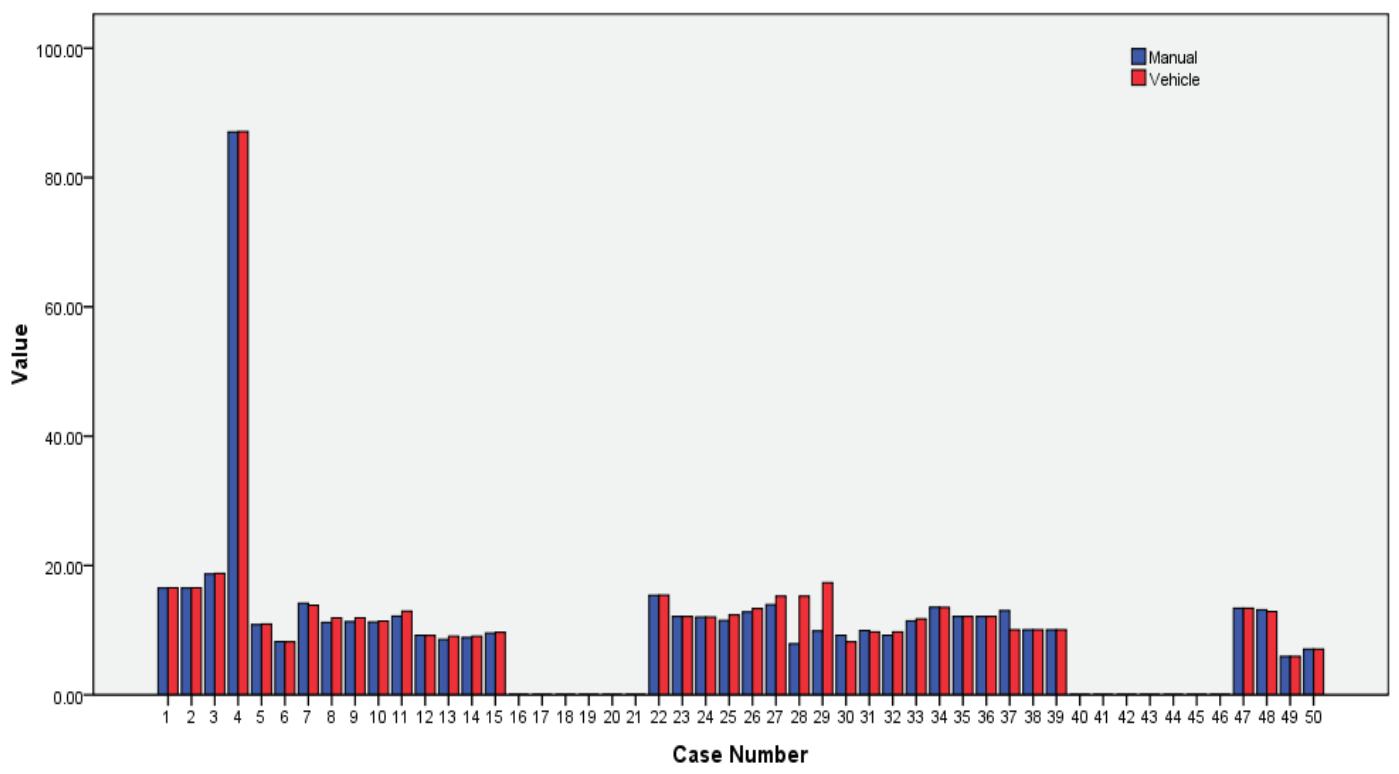

Figure 4 - Failure percentages from $35 \mathrm{~km}-35.2 \mathrm{~km}$ 
Table 1 - Paired Samples Test for a 95\% confidence interval

\begin{tabular}{|c|c|c|c|c|c|c|c|c|c|}
\hline & \multirow[t]{3}{*}{ Sample Pair } & \multicolumn{5}{|c|}{ Paired Differences } & \multirow{3}{*}{$\begin{array}{l}\mathrm{t} \text { test } \\
\text { result }\end{array}$} & \multirow{3}{*}{$\begin{array}{c}\text { Degree } \\
\text { of } \\
\text { freedom }\end{array}$} & \multirow{3}{*}{$\begin{array}{c}\text { Significant } \\
\text { (2-tailed) }\end{array}$} \\
\hline & & \multirow[b]{2}{*}{ Mean } & \multirow{2}{*}{$\begin{array}{l}\text { Standard } \\
\text { Deviation }\end{array}$} & \multirow{2}{*}{$\begin{array}{c}\text { Standard } \\
\text { Error } \\
\text { Mean }\end{array}$} & \multicolumn{2}{|c|}{$\begin{array}{l}\text { 95\% Confidence } \\
\text { Interval of the } \\
\text { Difference }\end{array}$} & & & \\
\hline & & & & & Lower & Upper & & & \\
\hline Pair 1 & $\begin{array}{l}\text { Manual Reading - } \\
\text { Vehicle Reading }\end{array}$ & -0.213 & 1.288 & 0.091 & -0.392 & -0.033 & -2.334 & 199 & 0.021 \\
\hline
\end{tabular}

Table 2 - Paired Sample Test for a 99\% Confidence Interval

\begin{tabular}{|c|c|c|c|c|c|c|c|c|c|}
\hline & \multirow[t]{3}{*}{ Sample Pair } & \multicolumn{5}{|c|}{ Paired Differences } & \multirow{3}{*}{$\begin{array}{l}t \text { test } \\
\text { result }\end{array}$} & \multirow{3}{*}{$\begin{array}{c}\text { Degree } \\
\text { of } \\
\text { freedom }\end{array}$} & \multirow{3}{*}{$\begin{array}{l}\text { Significant } \\
\text { (2-tailed) }\end{array}$} \\
\hline & & \multirow[b]{2}{*}{ Mean } & \multirow{2}{*}{$\begin{array}{l}\text { Standard } \\
\text { Deviation }\end{array}$} & \multirow{2}{*}{$\begin{array}{l}\text { Standard } \\
\text { Error } \\
\text { Mean }\end{array}$} & \multicolumn{2}{|c|}{$\begin{array}{l}\text { 99\% Confidence } \\
\text { Interval of the } \\
\text { Difference }\end{array}$} & & & \\
\hline & & & & & Lower & Upper & & & \\
\hline Pair 1 & $\begin{array}{l}\text { Manual Reading - } \\
\text { Vehicle Reading }\end{array}$ & -0.213 & 1.288 & 0.091 & -0.449 & 0.024 & -2.334 & 199 & 0.021 \\
\hline
\end{tabular}

As mentioned earlier, for a $99 \%$ confidence interval the SPSS output window gives the $p$ value as 0.021 and $\alpha$ value is 0.01 . The $p$-value is greater than 0.01 and this implies that the hypothesis has not been rejected. Therefore, there is no difference between the manual reading and vehicle reading at a $99 \%$ confidence interval.

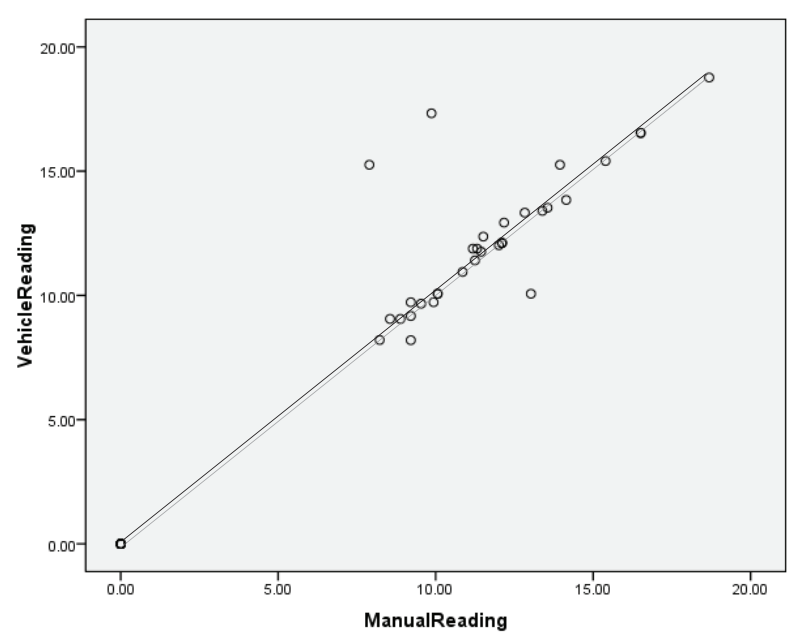

Figure 5 - Graph of Manual and Vehicle Reading Data

Table 3 - Paired Sample Correlations for 95\% and $99 \%$ confidence intervals

\begin{tabular}{|ll|c|c|}
\hline Sample Pair & $\begin{array}{c}\text { Number of } \\
\text { samples }\end{array}$ & Correlation \\
\hline Pair 1 & $\begin{array}{l}\text { Manual Reading \& } \\
\text { Vehicle Reading }\end{array}$ & 200 & 0.997 \\
\hline
\end{tabular}

Figure 5 represents the relationship of manual and vehicle readings for $35 \mathrm{~km}$ to $35.2 \mathrm{~km}$ chainages. According to that figure, there is a strong positive correlation between the manual reading and the vehicle reading. Hence both survey values are highly related.

Correlation values obtained for 95\% and 99\% confidence intervals are presented below.

For both confidence intervals, correlation values are obtained as 0.997 . These correlation values are close to +1 . Hence it can be predicted that data of both readings are highly related.

\section{Conclusions}

It was observed that manual and MFNSV inspection readings were almost the same. However, in some places differences between the two methods were noticed. Manual road inspection was carried-out after the MFNSV data collection. The time duration between the two inspections was around 5 months. It was assumed that there were no significant changes that have taken place in road failures during that time period. However, the gap in the duration in which the two surveys were done will slightly affect the difference in the two readings. For example, the cracks propagating along the road during that time are shown only in the manual inspection. In such places, manual reading takes a higher value than the MFNSV reading and in places where the failures were treated during that time belt the 
manual reading becomes lower than the MFNSV reading.

By conducting a sensitivity analysis it was found that the accuracy of the MFNSV inspection is quite high when compared with the manual road inspection. It was evident that, this vehicle can be recommended for inspection of long road stretches, since the manual method takes too much time and since it is labour intensive. Because of the high initial cost, conducting MFNSV inspection on short stretches is uneconomical. For such cases manual inspection is recommended.

\section{Acknowledgement}

Authors wish to acknowledge the help rendered by Mrs. D. Namalie Siyambalapitiya Director (Planning), Mrs. D. A. Pushpa Padmini Deputy Director (Planning), Mrs. G. K. Shayamalee Karunasekera, Senior Planning Engineer and the site engineers in the Planning Division of the Road Development Authority of Sri Lanka.

\section{References}

1. Hawkeye 2000 Series: Manual of Hawkeye Network Survey Vehicle, Australian Road Research Board (ARRB),

http:/www.arrb.com.au

2. Rees, D.G., Essential statistics, 3rd ed., Chapman \& Hall, London, 1995. 

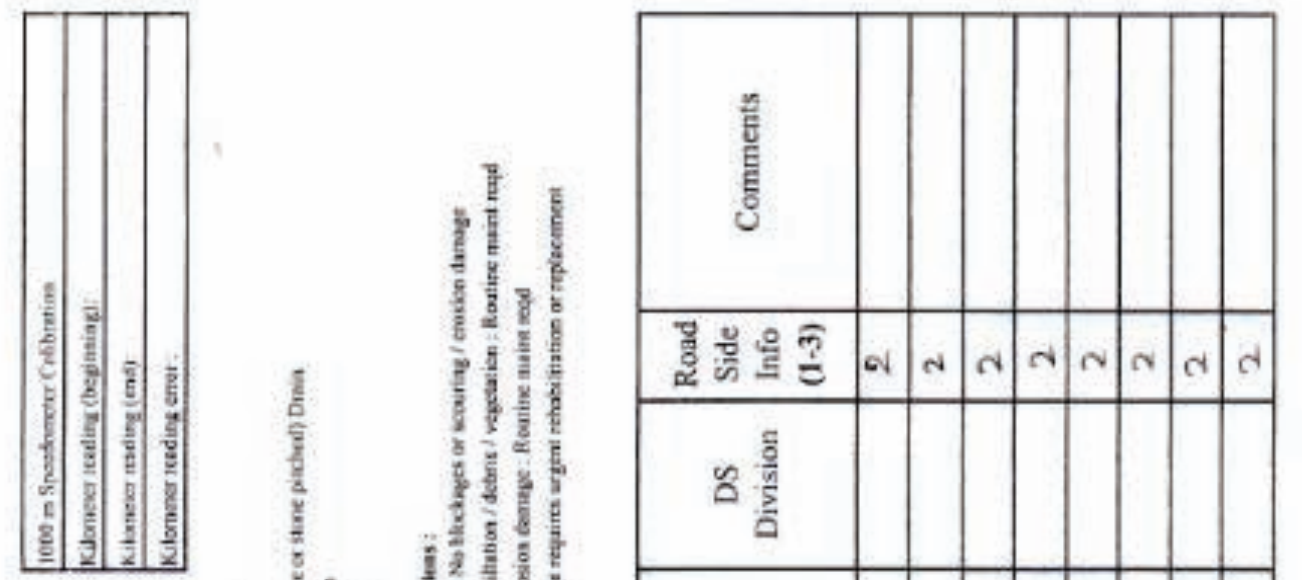

武
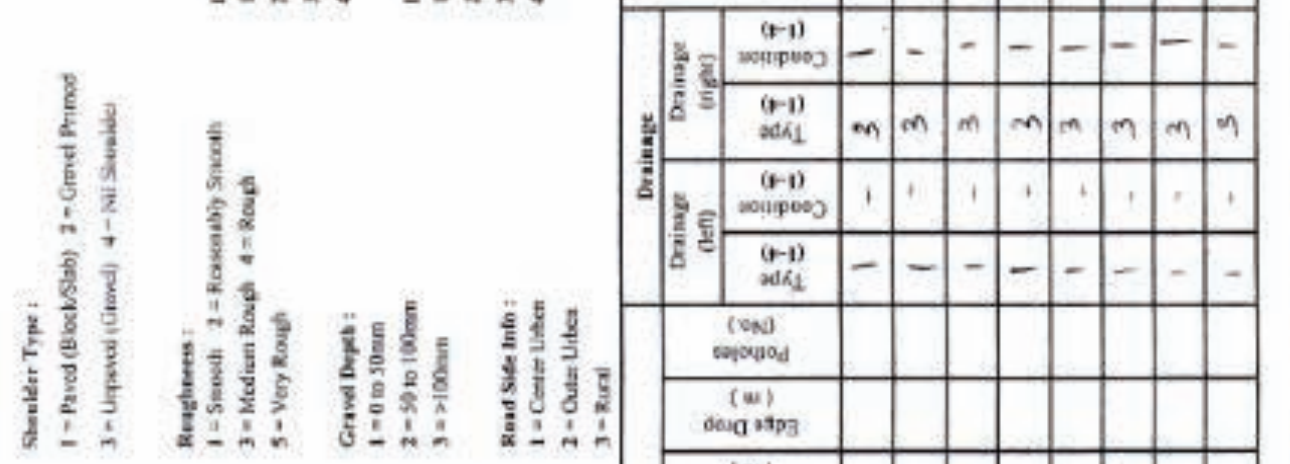

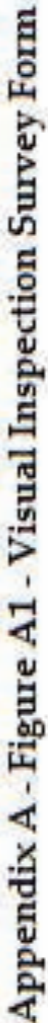

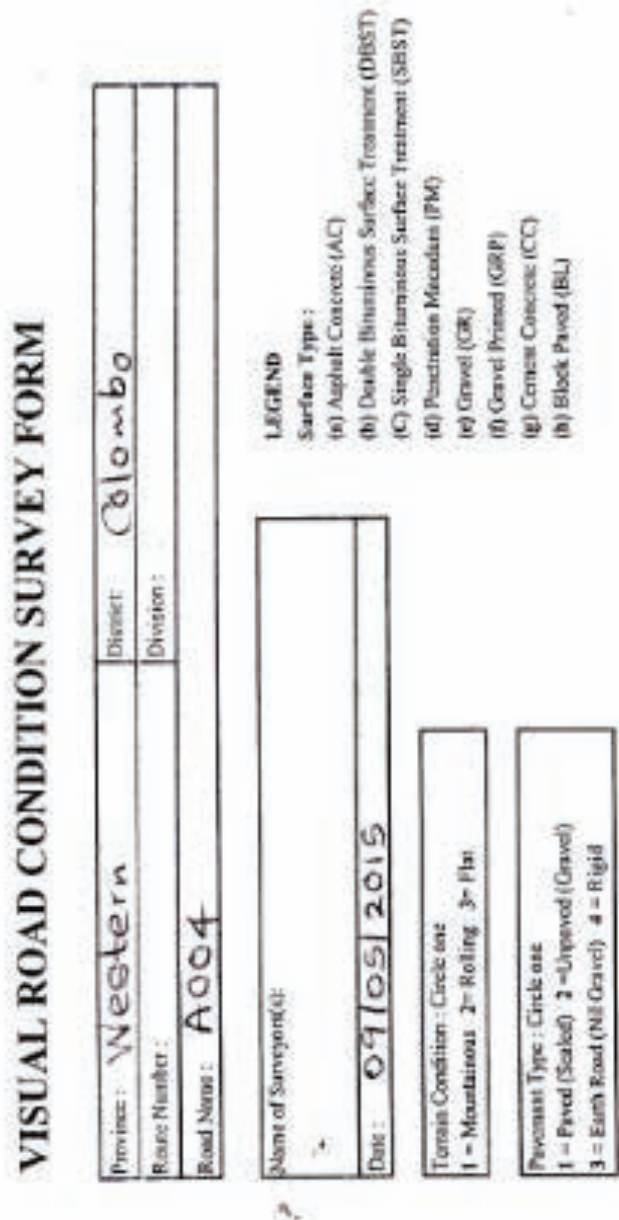

-
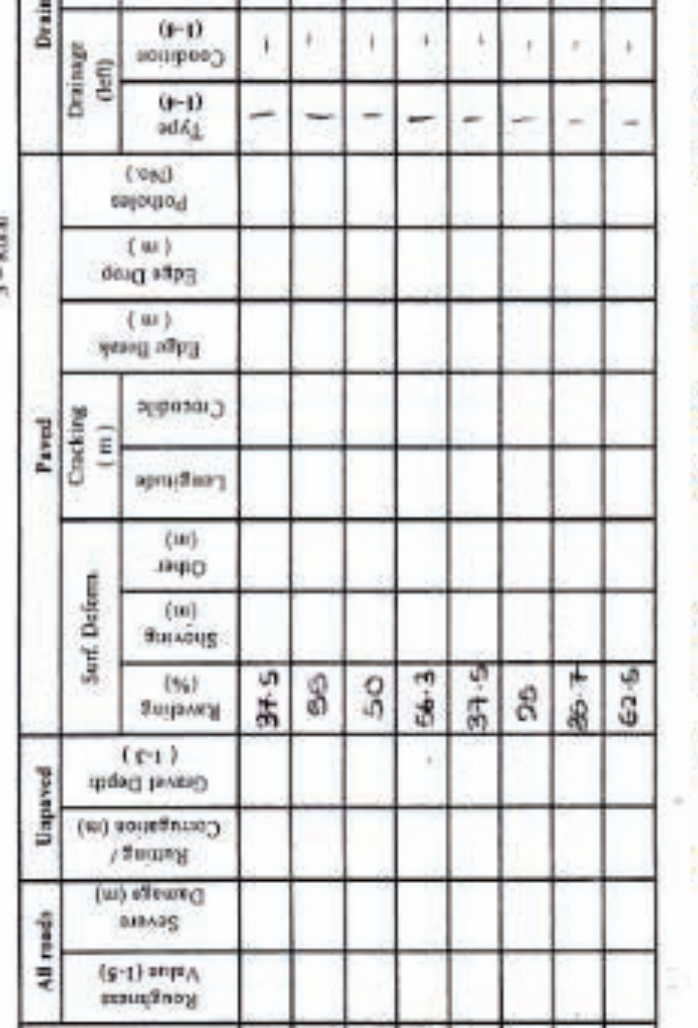

\begin{tabular}{|c|c|c|c|c|c|c|c|c|c|}
\hline \multicolumn{2}{|c|}{ 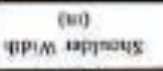 } & n) & की & ली & $\begin{array}{l}m \\
n\end{array}$ & $m$ & $m$ & $m$ & $m$ \\
\hline \multicolumn{2}{|c|}{ 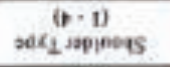 } & m & $m$ & $n$ & $m$ & m & $m$ & $m$ & $m$ \\
\hline \multicolumn{2}{|c|}{$\begin{array}{c}\text { (wi) } \\
\text { qpin proy }\end{array}$} & $\begin{array}{c}9 \\
1 \\
10\end{array}$ & $\begin{array}{l}4 \\
1-1 \\
\end{array}$ & $\stackrel{2}{2}$ & $\begin{array}{l}9 \\
+1\end{array}$ & $\stackrel{0}{1}$ & $\begin{array}{ll}0 \\
15\end{array}$ & $\begin{array}{l}0 \\
i\end{array}$ & If \\
\hline \multicolumn{2}{|c|}{ 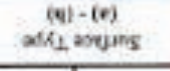 } & $\sigma$ & $\sigma$ & $\sigma$ & $\sigma$ & $\sigma$ & $\pi$ & $\sigma$ & б \\
\hline \multirow{2}{*}{$\begin{array}{l}\frac{1}{5} \\
\frac{0}{8} \\
\frac{8}{2}\end{array}$} & $2 \bar{g}$ & $\begin{array}{l}8 \\
6 \\
6 \\
\end{array}$ & $\begin{array}{l}5 \\
0 \\
6 \\
0 \\
\end{array}$ & $\begin{array}{l}0 \\
0 \\
0 \\
m \\
\end{array}$ & $\begin{array}{l}\frac{\pi}{0} \\
\text { c) } \\
\end{array}$ & 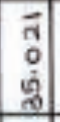 & \begin{tabular}{|l|}
0 \\
6 \\
6
\end{tabular} & $\begin{array}{l}\bar{y} \\
0 \\
\vdots \\
\pi \\
\end{array}$ & है \\
\hline & 를 & $\begin{array}{l}\overline{8} \\
\overline{8}\end{array}$ & $\begin{array}{l}8 \\
8 \\
\text { की }\end{array}$ & $\begin{array}{l}8 \\
8 \\
8 \\
\text { d }\end{array}$ & $\begin{array}{l}0 \\
0 \\
0 \\
0\end{array}$ & 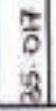 & {$\left[\begin{array}{c}\vec{c} \\
\hat{0} \\
\text { a. }\end{array}\right]$} & {$\left[\begin{array}{c}n \\
4 \\
0 \\
\vdots \\
5\end{array}\right]$} & $\begin{array}{l}5 \\
0 \\
6 \\
0\end{array}$ \\
\hline
\end{tabular}




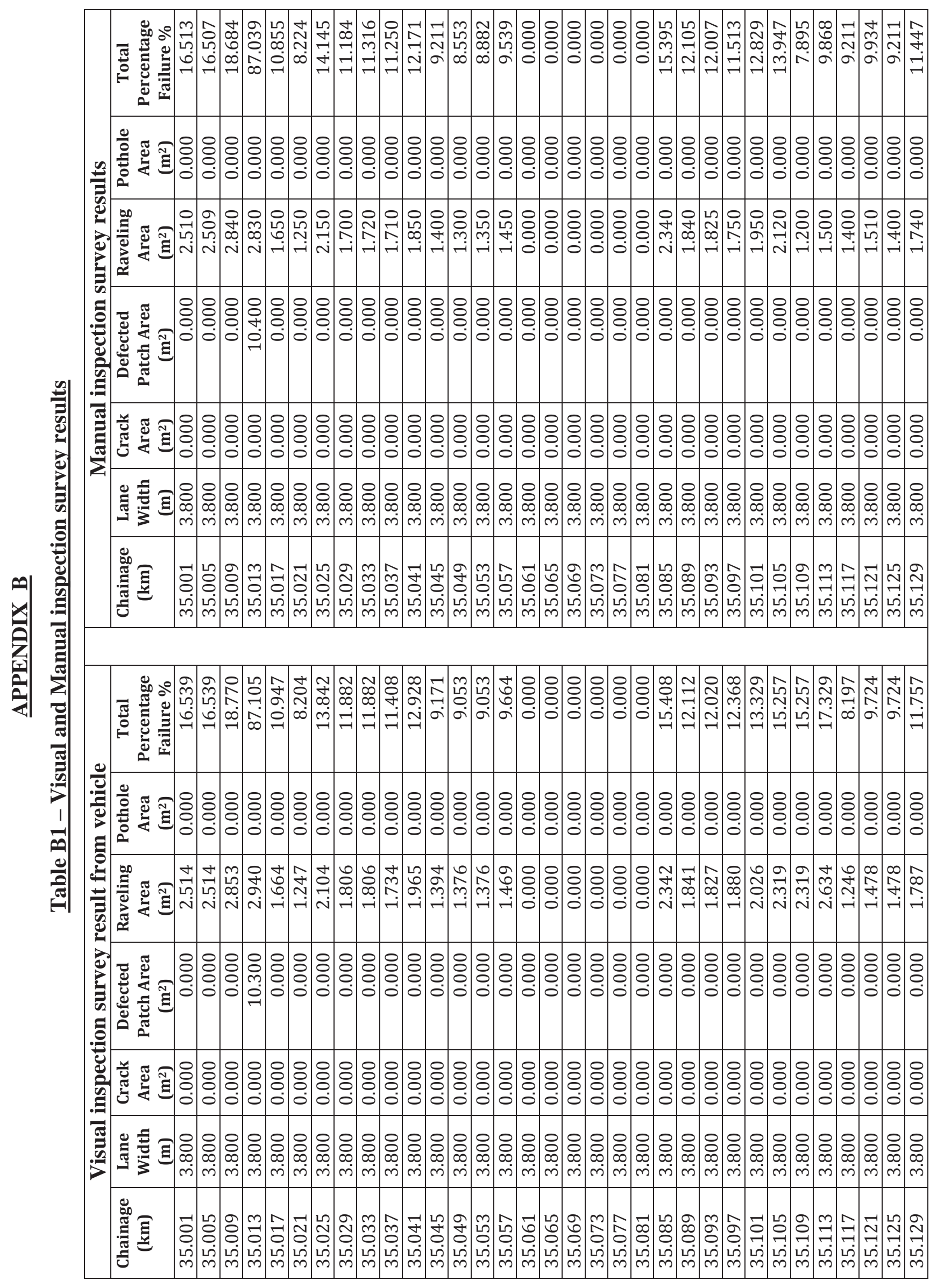

